\title{
The changing research context: Implications for leadership
}

Jennie Billot

AUT University, Auckland, New Zealand

Correspondence:

Dr Jennie Billot

Institute of Culture, Discourse and Communication

AUT University

Private Bag 92006

Auckland

New Zealand

Phone: 006499219694

Email: jbillot@aut.ac.nz

\begin{abstract}
Within the changing tertiary environment, research activity and performance are coming under greater pressure and scrutiny. External policy and funding directives are resulting in revised institutional objectives, requiring variations to organizational structures and processes. These changes impact on the relationship between the institution and the individual. Institutional executive provide benchmarks for revised activity and performance, while academic staff respond to new internal directives and accountabilities by reprioritising their responsibilities. At the same time, there will inevitably be an informal evaluation of the resourcing and support provided for staff as they experience the institutional push to attain greater research outputs. Within this dynamic environment there is the potential for tensions and negative outcomes if interactions are not carefully directed. The implications for leadership are obvious. What is less evident is whether the strategic intent of the institution resonates through the institution in alignment with the development of a supportive research culture.
\end{abstract}

Keywords: higher education research; research funding; research culture; leadership

\section{Introduction}

The call for tertiary institutions to address the needs of all stakeholders and perform more productively across all functions has stretched the concept of what constitutes 'research', how it is organised, as well as when, and which academics undertake this activity. While 'research' is acknowledged as having different meanings (Ball, 2007) it is also accepted as being an integral part of higher education (Tynan \& Garbett, 2007), although it is only one activity performed in a tertiary institution (Hansson \& Monsted, 2008). In the current context, as external demands oblige institutions to meet the requirements of funders, stakeholders and international competition, a major power shift is occurring within the tertiary sector (Mintrom, 2008). Now institutional managers and leaders need to pay greater attention to how they develop and operationalise the organisation's intersecting functions and position themselves within the competing 
sector. One outcome of this altered scene is the impact on how research utilities are accomplished.

Marginson (2000) has referred to the danger of research being policy led and research identities being colonised as a result of the new research economy. In this paper I examine the interface between the individual academic and the tertiary research context and the way in which institutional leadership exists within this research milieu. This focus may appear potentially too complex and multifaceted to easily unravel, but in the current changing and demanding research environment it is timely to examine how leadership can effectively facilitate academic research. Much has been written on the impact of funding regimes and research assessment exercises on an individual's identity and research performance (Churchman, 2006; Winter, 2009), as well as the increased accountability demands on institutions (Ashcroft, 2005; Clegg, 2008). Less comment has been made on how competently individuals are supported in achieving the outcomes prescribed by external imperatives, as well as their employing institution. This paper seeks to redress the dearth of extant literature in that theoretical space.

In the changing tertiary environment where accountabilities and expectations have been raised, Ball (2007) believes that leadership is the key to improved university performance, including research. During a time when there is a stronger need to retain a focus on academic standards, as well as address the new political economy of higher education (Rich, 2006), tertiary leaders need competencies to manage the evolving environment. This approach entails moving through the "inertia of an ossified system of academic organization" (p. 28) to create a responsive and effective working context and climate. Having personally experienced the tensions that exist between institutional and individual objectives, I offer theoretical perspectives, in combination with research findings, to unravel the complexity of identifying and achieving research goals. Firstly, I examine the changed milieu for research in New Zealand and then refer to project findings collected in a tertiary institution that identify issues pertinent to research productivity. As each university or polytechnic is different, it would be unwise to claim that leadership of tertiary institutions can be based on conceptual models. On the other hand, since organisational structures and processes influence individual output, the relationship between academics and executive is crucial for achieving institutional objectives. By extending the discourse on what comprises a thriving research climate, it becomes possible to propose how leaders can best guide academics through pathways that meet research objectives.

\section{Changing times for academics}

Change in the tertiary sector is not new, but academics and researchers have noted the increasing extent of this transformation (Marginson, 2000) as institutions attempt to meet the demands of multiple and disparate stakeholders (Churchman, 2006). The introduction of revised funding regimes, the requirements for technological uptake and further demands for acclimatisation to global trends and forces, all result in drivers for institutions in most countries to make rapid and sometimes complex responses. Unfortunately institutions are unwieldy in nature and it takes time to respond to the 
numerous and often conflicting pressures. Restructuring is one mechanism seen as useful for meeting external pressures, as is the incorporation of more managerial processes. Whatever the strategies employed, there are undoubtedly going to be some consequences since organisational changes resonate throughout the establishment (Debowski, 2007) often necessitating individual compromise and adjustment. While this paper focuses upon New Zealand, many of the issues arising from sector restructuring bear international comparison.

Within the last two decades, internationally, higher education has undergone significant changes with political decisions playing the major role in determining the structure of the tertiary sector (Sjolund, 2002). There has been an increased focus on economic viability, resulting in institutional competition within a market-driven environment (Goedegebuure \& Meek, 1997; Pratt,1999). These external imperatives have pressured institutions to respond strategically in ways that have changed the tertiary environment. In particular, academic work in higher education has been reshaped, particularly in the Western world, as the sector changes to become consumerdriven (Harris, 2005) and increasingly bureaucratised (Debowski, 2007). Such trends have been reflected within New Zealand where changes were propelled by the economic policies of the Labour government in the 1980s and supported by the actions of the National Government of the 1990s. New Zealand has had a lesser degree of restructuring than some of its international counterparts and an arguable decrease in the diversity within the tertiary sector seems to have occurred with the ability of non-universities to offer degree course (Codling \& Meek, 2003). Whilst these changes have encouraged polytechnics and newer universities to emerge as stronger tertiary providers, (Pratt, 1999), they do so within an environment where older, established universities move to assert their sector dominance.

In order to contextualize the institutional modus operandi, I refer here to the changed government funding model for research (and thus the institution itself) and the resultant tensions for leadership. While the changes referred to above have occurred across the whole sector and within most components of each tertiary provider, the effect on the research environment has been profound. Institutional funding from Government sources in New Zealand research is now partially based on the Performance Based Research Fund (PBRF), whereby institutions receive income reflecting the PBRF graded status of their individual members. This is in contrast to the UK where departments within an institution are allocated a grade for funding (Blackmore \& Wright, 2006; Lucas, 2006). The PBRF is effectively an outcomes-based model, where achievements are recognised to a greater degree than research inputs and related activities. This mode of funding demands that institutions reach certain performance levels and so they strategise to meet increased competition and changed expectations. The resulting consequence is a changing academic role (Middleton, 2005) and increased tension for individual academics as they juggle teaching, research and administrative responsibilities. As academics grapple with revised and increasing expectations, they prioritise their activities, not only to address institutional accountabilities but also to fulfil their perceived role as an academic. Whilst undertaking research was once the domain for only certain academics, there is now pressure for the majority of academics 
to be involved in research activities. For many, the objective is now the production of defined research outputs.

This changing research context requires all parties to work in concert to meet common goals. The challenge is to facilitate such collaboration. Since tertiary institutions are essentially organisational establishments, their functions will depend upon both operational and personnel structures. The chain of authority is located within a defined procedural landscape and strategic intentions are created and implemented through prescribed channels. Given that the effectiveness of defined activities is influenced by the clarity of management, it is essential to have competent internal governance. Decisions on the need to cut expenses, reduce or eliminate courses or maximise research performance hinge on the presence of faculty expertise as well as the need for executives to responsively meet directives beyond the campus walls. While Gumport (2001) has questioned the adoption of "imperatives and values from corporate settings" to achieve "efficiency and flexibility" (p. 242), the reality is that institutions are responding to the call to do so. So the challenge lies in aligning the objectives of all parties, to achieve not only economic sectoral demands, but also retain a focus on the other functions of the institution. Gumport has also noted that as universities re-structure in relation to changed priorities, this involves changed resource allocation and possible "stratification of who and what matters" (p. 250). Such issues are relevant for the work and study environment and the level of staff engagement.

The shift to meet the demands of the market and public interest, while simultaneously providing a setting for learning and the extension of knowledge, tests the quality of institutional leadership. Short term managerial reactions can involve the reshaping of internal management in conjunction with pressures for improved efficiency and increased entrepreneurship (Winter, 2009). This may put at risk the activities that academic staff believe are fundamental to their role. Since these mechanisms have all contributed to a more commercialized institutional environment, of necessity then, tertiary institutions have had to adapt, change and re-design their mission for continued quality educational provision and research productivity. By default the responsibility for these changes has fallen on the shoulders of those in positions of leadership. In his research Ramsden (1998) found that staff perceptions of effective leadership had a strong correlation with productivity. When "clear goals, a climate of respect and cooperative authority structures" are present, they facilitate optimal conditions for "professional activity and productivity" (p. 72). How leaders bring about this environment is therefore crucial for effective outcomes.

If institutions have an increased need to accelerate research productivity and leadership is a crucial element in that objective, how do more academics develop research skills and capability to accommodate institutional demands? By referring to a project undertaken in a New Zealand institute of technology, I illustrate the way in which staff can be supported to meet the expectations of the national and institutional research agenda. While individual academics can react to staff research resourcing with scepticism and cynicism, it is how institutional leaders and academics work together that will effect a satisfying and productive mode of researching. 


\section{Findings from within a New Zealand polytechnic}

As institutions are being pressured to make strategic choices about organisational, human resource, funding structures and resource allocation, so these options have repercussions on the positioning and support of academic staff. Notionally, a research 'culture' provides an environment that supports and enhances the research activities of academics. The term 'culture' supposes that a unified purpose exists amongst colleagues in their search for both individualised and institutional advancement. In reality, this environment may not be present. Diverse disciplines and conflicting institutional structures can result in a mosaic of separated entities. So how are academics encouraged to increase research activity and how can this be meshed into a 'culture' within the organisation?

In order to understand what comprises a healthy and supportive research culture, I undertook a research project in a polytechnic which had been aspiring to university status throughout the late 1990's and early 2000's. In order to meet the prescribed criteria, the institutional leadership led initiatives to increase research performance. A significant challenge for the executive was to address the wide disparity in expertise across the disciplines and departments. Mechanisms were needed to integrate the research productivity of the more experienced staff and professoriate, with the less experienced and novice researchers. This situation was exacerbated by the fragmented research culture within the polytechnic. Many staff were primarily focused on teaching, did not want to undertake research and had little time allocation for researching. Such tension only served to complicate the institutional need to work speedily to change these conditions. With the PBRF providing impending research assessment dates and the time lag that exists between research activity and final publication, any strategies or restructuring within the polytechnic required more haste than was desirable.

The project was qualitative in nature and involved data collection from 41 staff through an online survey, followed by 14 semi-structured interviews. The participants included academic staff across 3 specific disciplinary departments (schools) in the institution (Education, Design and Nursing) as well as the Executive Director of Research. A focus for the data collection was to access staff perceptions of how an externally driven research performance model affects the individual academic. Unfortunately, being a polytechnic meant that budgets did not easily permit concomitant resourcing of academic efforts. Survey and interview data identified a mismatch of institutional support and staff performance. On the other hand, the findings did highlight those aspects of a research environment that appear to be essential for research enhancement.

The survey findings identified that one third of the sample had submitted research portfolios for assessment in the two PBRF evaluations of 2002 and 2006. This had some correlation with the degree of experience that the respondents indicated. Of the 41 staff, only 30 per cent had more than 12 years tertiary experience and 42 per cent 
had less than 3 years. 28 out of the 41 staff surveyed classified themselves as 'research active' but only one third had been involved in collaborative projects. Notably, 73 per cent of staff stated that the institution did not provide 'adequate' research support.

Staff were asked how much more emphasis they now give to research over other commitments. 33 per cent indicated that they now prioritise research to 'a greater extent'; 49 per cent to 'some or small extent' and 18 per cent 'not at all'. Interestingly, when asked a similar question about any change of emphasis given to teaching, 17 per cent had to a 'great extent'; 36 per cent to 'some or a small extent' and 37 per cent 'not at all'. One way in which some staff had managed to increase research productivity was by 'protecting' research time. 27 per cent had done this to a 'great extent' and 21 per cent to 'some extent'.

Mixed views were expressed on how the institution had been shaped by the demands of the PBRF. The common response was that increased institutional expectations had initiated a division between teaching and research (an ironic acknowledgement since research and teaching are heavily inter-twined and are encouraged to be so), adding pressure on staff and introducing concern for those not doing research. Other observations included how "people are now less generous and cooperative as the structure is so individually designed" while positive reactions included a reference to the encouragement provided for staff to complete further qualifications.

From the survey, the major characteristics that comprise a 'supportive research environment' were listed as time allocation, funding, and a 'positive culture'. Significantly, accountability and transparent processes were also listed as important. Not all respondents were aware of institutional expectations and while this was emphasised in later interview transcripts, it was also noted in these interviews that not everyone knew what their department/school required of them either. The major challenges were related to those features reported as missing from a supportive research environment, namely, sufficient funds, workload balance, and administrative commitments. Ways to address the problems/challenges that staff identified as inhibiting their ability to be an 'effective' researcher, included a clearly defined working model (clarity of role expectations) mentoring, incentives, more time, institutional recognition, funding for conferences, sabbaticals and other forms of support.

The interviews were illuminating. (Quotes provided here will be appended by the participant code). The discussion with the Executive Director of Research provided the background for the change at the polytechnic where stress was placed on objectives, procedures and processes. In order to develop a revised research focus for the institution, strategic goals had been set by the executive, focusing on increasing the quality and quantity of research outputs. Since it was acknowledged that this outcome depends on both research capability as well as staff productivity, efforts were made to encourage individuals to 'contribute' to the research environment (a category of assessment in the PBRF) in varied ways (such as mentoring, peer support etc) in order to modify the research ethos. Other initiatives included the availability of project funding, research awards and the creation of school research committees to support newer researchers. At 
the same time, the professoriate was financially incentivised to support newer researchers.

The interviews with academic staff provided a perspective on how these strategies had worked at the 'grass roots' level. Heads of schools tended to be more optimistic and keen to identify measures taken to bolster staff productivity. Their comments focused upon both processes and individuals, although they acknowledged that sometimes they felt constrained in their role, by insufficient institutional funding and support. For these individuals, developing a research culture involved changing staff perceptions of their responsibilities, at the same time as encouraging through more practical mechanisms. "I am wedded to the notion that the culture is about the way we solve our problems and those ways of solving problems become embedded in the memory of people that we work with" (RC05). Another head of school couched the issue in these terms: "It is a culture I would ideally suggest that would put incentives in place for staff, that would reward staff, that would then encourage staff.” (RC07).

Interviewees viewed a research culture as having both "pressure and support" with "staff who have to want to belong" (RC05). Another interviewee put it this way: "I guess being supported to do the research if that's the path you go down. The recognition of the value of that...celebrating success...recognition when there's a publication...being supportive in terms of time” (RC04). Others phrased it thus:

I suppose the word culture's about how it fosters research and how it reflects research. So I think to some extent that has to be measured in outcomes. So you know, a research culture is a group of people or an occurrence where there is more research, but at the same time I think culture to me means that there's a wider commitment and concern to foster growth and capacity. (RC10)

I think research culture means the way that you, as a group, or for us as a school, understand research and pursue it and that's the shared understanding. [It's] a way of working with and talking about and understanding research that we have as a school. The supportive research culture would be one where all levels of research were valued depending on peoples, you know, point in their research journey. (RC011)

In some cases, staff expressed a stronger affiliation for the school and the help offered within it, than the institution as a whole, since school mechanisms of support were often viewed as more accessible and appropriate for the research discipline. However, frustration was expressed about the disconnect between school and executive, and the lack of filtering of external funding back to the school and the individual. One head of school in particular was concerned about the way in which executive had lost touch with the roles and responsibilities of individual staff. 
I get really frustrated that there is a one size fits all approach when it comes to research and let me explain that. I've sat in enough academic, senior academic meetings and management meetings where people say every staff [member] has to have at least two published refereed outputs per year, there is no excuse, but these are the same people who only have 10 or 12 contact hours a week and they don't have the pressures of practice on top of that...(RC07)

This snapshot of the project findings identify how perspectives differ throughout the organisational structure. These staff perceptions of research, culture and the degree of alignment between managerial expectation and support, provide insights into the professional divide between the academic manager and the managed academic (Winter, 2009). In addition some staff have indicated a view similar to that articulated by Ramsden (1998), that there is a "depressingly one dimensional view of academic status which [is] encouraged by research performance measures" (p. 183). There is a risk that if less attention is given to the connections between staff as individuals and the executive directives, then outcomes remain isolated as end products, rather than incremental features within a healthy research context. The voice of academic staff remains clearly articulated, as summarised by this interviewee:

People in formal roles of leadership need to remove the obstacles that prevent those people from doing research. It's a two way thing. Critically what sits underneath that is having dialogue with people, not discussion but dialogue. If people are open and transparent at that level and also about the processes, it creates trust. (RC09)

\section{Enhancing a research climate: Leading research}

Mintrom (2008) identifies two mechanisms that executives could effectively utilise in concert to enhance institutional reputation (with funders and other partners) and improve research performance. Policies need to be revised to emphasise the significance of such productivity and this tacit pressure needs to be complemented by incentives to "promote and reward strong research effort on the part of individuals and whole academic units" (p. 238). Performance management processes can assist with monitoring academic practice, but care is needed to prevent the stick being more overt than the carrot. Individual academics do not respond well to over-zealous scrutiny and pressure. Madden (2009) observes that "suitable management of researchers within an ideal environment would ensure the right combination of recognition and reward” (p. 281).

Thus management and leadership need to be dovetailed into a collaborative effort. The role that leaders play may be viewed differently than the manner in which an institution is managed for as Geller (2002) states, "simply put, managers hold people accountable, whereas leaders inspire people to feel responsible” (p. 31). Geller also believes that leaders will instigate and encourage dialogue on how best to operate processes that effect desired outcomes. In contrast, while managers "obtain their 
influence by controlling other peoples' consequences, leaders go beyond consequence control" (p. 29) and "use consequences directly or indirectly to influence employee behaviours in directions that benefit a work unit or the organisation as a whole” (p. 30).

Conventionally, academics have shied away from management and administration, including academic leadership positions, having a preference for being "unencumbered by organizational demands" (Rich, 2006, p. 40). In some cases this reticence is due to the unwillingness to engage in activities less suited to academic competencies, and in other cases, individuals prefer to undertake roles that do not involve administrative problems. Whatever the reasons for the academic caginess around the assumption of leadership and management roles, it is becoming increasingly obvious that the academy requires the dovetailing of both academic and leadership functions.

Leithwood, Jantzi and Steinback (2003) have pointed to the wide variation in contexts for leadership and the need for context-specific responses. They also stress that "what is important is how leaders respond to the unique organisational circumstances or problems that they face” through "contingent leadership" (p.15). Thus within the polytechnic referred to above, the priority is to manage the institutional objectives whilst also enabling a working environment that supports and enhances research outcomes. This refers to the need for "a degree of accountability, [but also] a huge degree of transparency in what's expected of people" (RC05). Significantly, some issues need to be aimed for, while others need to be avoided. In order to retain and attract research active staff to the institution, executive need to ensure that efforts to enhance productivity do not fuel competition between staff creating an environment of distrust and unpleasant working conditions (Mintrom, 2008). Staff engagement is a priority as this attitude would avoid the frustration expressed by a project participant:

Well I actually think the expectations of both the school and the institution are entirely unrealistic...we have large classes and a very heavy workload and yet the expectation of us in terms of producing research outputs doesn't change at all and there's no extra support in terms of teaching for us, which would then enable our research outputs to increase. So I am an entirely frustrated active researcher to the point where I'm practically inactive. (RC14)

\section{Conclusion}

There are implications for research leaders. Leadership is a fundamental part of any future development of the tertiary sector. Circumstances that are part of the reconfiguration of the tertiary sector will inevitably keep changing, so it falls to those who lead the change to maintain institutional-individual equilibrium. Yet the pressure for leaders to work towards the broader institutional objectives may result in a disconnect between institutional and individual performances. There is an obvious need to support academics in identifying new goals and relating productively within the changing environment. 
Tertiary institutions undertake research for both internal and externally driven purposes. Whatever the institutional priorities, research remains an integral part of any university's strategy and university activity (Ball, 2007). Jarvis (2001) has referred to research as being the essence of the university where it is viewed as a traditional endeavour, although debate over what 'research' is continues, especially within tertiary research assessment regimes where certain forms of research are more highly regarded than others. More recent pressures within the tertiary sector for institutions to perform and reach externally prescribed standards has meant that internal mechanisms that drive and support increased research performance have received more attention. The demands from the external bodies flow through the institution to lean heavily on the individual researcher. Studies in the UK and Scotland (Deem \& Lucas, 2007; Gordon, 2005) and New Zealand (Middleton, 2005) have linked research assessment regimes to growing discontent and frustration for individual academic researchers.

The study of a polytechnic illustrates the tensions between the aim to increase research productivity and staff engagement. To attain university status required a boost to its research productivity but using pressure without the support has caused much individual disturbance. This is not unexpected in an institution where organisational and individual expectations meet the complexity and heterogeneity of the academic community (Silver, 2003). A study by Madden (2009) identified the type of environment that is most conducive to research. He noted that while optimal conditions vary with discipline, certain characteristics are commonly identified. Research is encouraged through the provision of opportunities and time to converse with colleagues and other academics. These inter- and intra-disciplinary exchanges often promote the initiation and pursuit of projects. The issue of time allocation appears to be crucial for academics in order that there is space to reflect as is the support to develop research skills. While staff identified these environmental components as supportive of research, it was also apparent that there needed to be a level of job security and institutional acknowledgement of staff contributions. Without these personal and employment actions, there is a danger that staff may lack loyalty to employer and project.

Change can be unsettling, so institutional adjustments through to major restructuring need to be transparently facilitated. Since the ethos of the organization and staff morale are crucial (Mintrom, 2008), how the research context is designed and enriched is of great significance. Characteristics of a supportive research environment have already been referred to, but whose responsibility is it to sustain a research culture? Schein (1986) suggests that an institutional culture should reflect "the pattern of basic assumptions that the group has invented, discovered, or developed in learning to cope with its problems of external adaptation and internal integration and that has worked well enough to be considered valid” (pp. 30-31). Essentially when research productivity is significant for the sustainability of the institution, it is crucial that all staff at all levels work in concert.

Strong, relevant and contingently practised leadership (Turner, 2003) provides a mechanism to operate at the interface of the organization and the individual. Gronn 
(1996) identifies leadership as working through influence and identification, facilitating organizational objectives through a cohesive research culture in which individual academics can feel supported to research. Effective leadership and management of the research environment would include adequate resourcing, mentoring and supervision, so that emerging researchers can be appropriately introduced to the research process. By using the experience of more seasoned researchers, research capabilities can be elevated. When academic staff are acknowledged for their publications and research activities, it can encourage stronger research engagement. Practical actions that tertiary leaders can take include the provision of bridging funds to support researchers between contracts; the establishment of inter-disciplinary research centres that provide research capacity and capability; adequate administrative support to free up staff to undertake research; and management training for project managers. It has been identified in a current study by Billot and Codling (2010 forthcoming), that the alignment of institutional and individual objectives and practices is essential for their successful fulfilment. Consequently, in the tertiary environment where the community is viewed less as a collective and more as a "mosaic" or "kaleidoscope" of staff (Whitchurch, 2008, p. 88), there is a call for leadership that is transparent in practice, clear in communication and engendering of collegial trust. The combination of such leadership with a healthy and supportive research environment, provides some way forward in a rapidly changing research environment.

\section{Reference list}

Ashcroft, C. (2005). Performance based research funding: A mechanism to allocate funds or a tool for academic promotion? New Zealand Journal of Educational Studies, 40(1), 113-129.

Ball, S. (2007). Leadership of academics in research. Educational Management, Administration \& leadership, 35(4), 449-477.

Blackmore, J., \& Wright, J. (2006). The quality agenda and some issues for educational research and researchers: an introductory essay. In J. Blackmore, J. Wright \& V. Harwood (Eds). Counterpoints on the quality and impact of educational research. Review of Australian Research in Education, 6, The Australian Educational Researcher Special Issue, 1-18.

Debowski, S. (2007). Challenges and dilemmas for Australian academics. HERDSA News, 29(3), 21.

Churchman, D. (2006). Institutional commitments, individual compromises: Identityrelated responses to compromise in an Australian university. Journal of Higher Education, 28(1), 3-15.

Clegg, S. (2008). Academic identities under threat? British Educational Journal, 34(3), 329-345.

Codling, A., \& Meek, L. (2003). The impact of the state on institutional differentiation in New Zealand. Higher Education Management and Policy, 15(2), 83-98.

Debowski, S. (2007). Challenges and dilemmas for Australian academics. HERDSA News, 29(3), 21. 
Deem, R., \& Lucas, L. (2007). Research and teaching cultures in two contrasting UK policy contexts: Academic life in Education Departments in five English and Scottish universities. Higher Education, 54, 115-133.

Geller, E. S. (2002). Leadership to overcome resistance to change: It takes more than consequence control. Journal of Organisational Behavior Management, 22(3), 2949.

Goedegebuure, L., \& Meek, V. L. (1997). On change and diversity: the role of government influences. Higher Education in Europe, 22(3), 309-319.

Gordon, G. (2005). The human dimensions of the research agenda: Supporting the development of researchers throughout the career life cycle. Higher Education Quarterly, 59(1), 40-55.

Gronn, P. 1996. From transactions to transformations: A new world order in the study of leadership? Educational Management and Administration 24(1): 7-30.

Gumport, P. J. (2001). Restructuring: Imperatives and opportunities for academic leaders. Innovative Higher education, 25(4), 239-251.

Hansson, F., \& Monsted, M. (2008). Research leadership as entrepreneurial organising for research. Higher Education, 55, 651-670.

Harris, S. (2005). Rethinking academic identities in neo-liberal times. Teaching in Higher Education, 10(4), 421-433.

Jarvis, P. (2001). Universities and corporate universities. London: Kogan Page.

Leithwood, K., Jantzi, D., \& Steinbach, R. (2003). Changing leadership for changing times. Berkshire: Open University Press.

Lucas, L. (2006). The research game in academic life. Buckingham: Open University Press

Madden, A. D. (2009). Managing for the ideal research environment. Journal of Higher Education Policy and Management, 31(3), 271-282.

Marginson, S. (2000). Rethinking academic work in the global era. Journal of Higher Education Policy and Management, 22(1), 1-12.

Middleton, S. (2005). Disciplining the subject: The impact of PBRF on education academics. New Zealand Journal of Educational Studies, 40(1), 131-156.

Mintrom, M. (2008). Managing the research function of the university: pressures and dilemmas. Journal of Higher Education Policy and Management, 30(3), 231244.

Pratt, J. (1999). Policy and policymaking in the unification of higher education. Journal of Education Policy, 14(3), 257-269.

Ramsden, P. (1998). Learning to lead in higher education. London \& New York: RoutledgeFalmer.

Rich, D. (2006). Academic leadership and the restructuring of higher education. New Directions for Higher Education, 134, 37-48.

Schein, E. (1986). What you need to know about organisational culture. Training and Development Journal, 40(1), 30-31.

Silver, H. (2003). Does a university have a culture ? Studies in Higher Education, 28(2), 157-169.

Sjolund, M. (2002). Politics versus evaluation: The establishment of three new universities in Sweden. Quality in Higher Education, 8(2), 173-181. 
Turner, C. (2003). A critical review of research on subject leaders in secondary schools. School Leadership and Management, 23(2), 209-227.

Tynan, B.R., \& Garbett, D.L. (2007). Negotiating the university research culture:

Collaborative voices of new academics. Higher Education Research \& Development, 26(4), 411-424.

Whitchurch, C. (2008). Beyond administration and management: Reconstructing the identities of professional staff in UK higher education. In Barnett, R. \& di Napoli, R. (Eds.), Changing identities in higher education: Voicing perspectives (pp. 6988). Abingdon: Routledge.

Winter, R. (2009). Academic manager or managed academic? Academic identity schisms in higher education. Journal of Higher Education Policy and Management, 31(22), 121-131. 